\title{
Potential of inverted process-chain development to improve crash box performance
}

\author{
Nima Jafarzadeh Aghdam ${ }^{\text {1*, }}$ Yannik Sparrer ${ }^{2}$, Jannik Zimmermann', Konrad Arno Gregor Mäde ${ }^{3}$, \\ Rahul Sharma $^{3}$, Uwe Reisgen ${ }^{3}$, Kai-Uwe Schröder ${ }^{1}$ and Sebastian Münstermann ${ }^{2}$ \\ 1 Institute of Structural Mechanics and Lightweight Design (SLA), RWTH Aachen University, 52062 Aachen, \\ Germany \\ 2 Integrity of Materials and Structures (IMS), Department of Ferrous Metallurgy (IEHK), RWTH Aachen University, \\ 52072 Aachen, Germany \\ 3 Welding and Joining Institute (ISF), RWTH Aachen University, 52062 Aachen, Germany \\ * Correspondence: nima.aghdam@ sla.rwth-aachen.de; Tel.: +49 2418096651
}

\begin{abstract}
Currently, components, processes and materials are mainly developed independently. However, to exploit the full potential of modern materials in component design, integrative development work is necessary. Component performance-based requirements and corresponding local material properties must be taken into account. In this work, a component-driven approach and therefore an inverted process chain is presented and demonstrated on the performance of a crash box, produced from DP600 steel. This is aimed to increase the energy absorption of the crash box without losing progressive buckling behavior. The finite element simulations were carried out on the crash box. It was shown that the crash box corners play an important role in the crash box performance, and required material properties for improving the crash box performance were derived based on the simulations. Heat treatment strategies were afterward developed and experimentally validated to fulfill these requirements. Then different local heat-treatment processes were applied to the corners of the crash boxes and tested experimentally. The experiments results validate the potential of the inverted process chain to improve the components performance. Furthermore, in this paper, optimal material properties were extracted for crash box strengthening, which lead to high energy absorption and a low peak force of it.
\end{abstract}

Keywords: Gradient microstructure, local heat treatment, square crash box, axial crushing, DP600 steel, peak force

\section{Introduction}

Crash boxes are thin-walled tubes, which are used widely for energy-absorption purposes in collisions. Hereby, the kinetic energy of an impactor is converted by continuous folding into plastic deformation of the crash box. Different aspects should be considered in a crash box design. In the last decades, a considerable amount of research was conducted on the mechanisms of crash boxes. Several approaches have been introduced for estimating their energy absorption [1-3]. Progressive buckling is a prerequisite for the crash box function. Buckling of a tube is progressive when it produces several local folds (wrinkles) along the structures under axial loading. The progressive buckling of crash boxes has been studied in several research works [4-8]. The crash box peak force is another important aspect of a crash box design. Axial crushing of thin-walled tubes leads to a high initial peak force, which is related to the first fold creation on the tube. A high peak force endangers protected structures and passengers' safety [9]. Apart from the mentioned aspects, cracking in corners [10] and global-stability failure [4,8] of the component should also be considered in the crash box design. Comprehensive books and review papers have been published on crash box analysis [11-15]. Even though a considerable amount of research has been devoted to crash boxes, they require constant improvements due to the demand for increasing passengers' safety and lightweight design concerns.

Different studies have been conducted to improve crash box performance. Materials optimization and also foam filling effects were studied in [16-19]. It is reported that the foam filling can enhance the energy absorption, even though the exact response of the cellular material to dynamic loading is not yet comprehensively understood. Wang et al. used a multi-objective optimization approach in combination with a biomimetic-inspired lattice filling of the crash box to improve its crashworthiness [20]. Besides the material approaches, geometrical approaches are also widely used to improve the energy absorption. Jones et al. studied the effect of stiffening elements on crash box efficiency [21]. The stiffeners were joined to the inner and outer surface of the crash box to increase the crash box energy absorption. Even though the energy absorption was increased, the stiffeners also increased the chance of crash box global buckling. External linear-gradient grooves 
effect on crashworthiness of the circular tubes was studied by Yao et al. [22]. The crashworthiness design of the windowed tubes under axial loading was studied by Nikkhah et al. [23]. Multi-cell tubes as a replacement for typical tubes have been studied in several research papers [13,18,24,25]. The studies revealed that increasing the number of the corners results in energy-absorption raise. Thickness grading and corrugating effect on the multi-cell tube performance have been studied by Fang et.al [26] and Li et al. [27]. Zhang et al. have studied the thickness grading effect on energy absorption of hollow square tubes [28]. They reported that the grading can increase the energy absorption up to $30 \%$ without increasing the crash box peak force. This thickness grading can be achieved by different process strategies [29], e.g., flexible rolling, which is used to produce tailor rolled blanks [30], or adapted welding processes to manufacture tailor welded blanks [31]. The crash box manufacturing itself was investigated by Dimirci et al. who characterized the influence of spot welding in crash box assembly regarding its performance [32].

Additionally, local heat treatment has been introduced in the literature to improve crash box performance. Bambach et al. [33] have used laser heat treatment to obtain spatially graded components to control folding patterns of crash boxes. By applying the same crush energy, the crushing distance of the crash box decreased almost by $28 \%$ due to the strain-hardening engineering. Similar results were reported by Quadfasel et al. who also used strain-hardening engineering to enhance the material properties and thus the crash box efficiency [34]. The optimization resulted in a 35\% weight reduction of the crash box. Conrads et al. [35] have used local heat treatment for increasing the energy absorption capacity of the crash box and also increasing ductility at the corners of the steel crash box to prevent crack initiation. Based on their results, the locally heat-treated crash box in comparison to the fully-recrystallized crash box can absorb the same amount of energy with $17 \%$ less crushing distance. The high effect of the crash box corners on energy absorption is reported by other researchers as well $[26,28,36]$. However, the local heat treatments affect also other crash box features such as peak force and progressive buckling, which need to be considered to design an optimized crash box. Contrary to the laser heat source, which has been used by Bambach et al. [33], Hosseini et al. used an arc heat treatment technique to produce graded microstructures through controlled temperature gradients [37]. A comprehensive review on different approaches to improve crash-box performance is provided in [13].

Most of the existing design and optimization approaches of the thin-walled crash box can be categorized into geometrical-based, material-based and process-based approaches. Usually, if a novel steel alloy is developed its application on the crash box is investigated regarding the energy absorption. The same applies if a heat treatment method or forming process is refined. Whereas in this paper, an integrative method is established, which can be seen as an improvement of the current component design: From a material-focused structural design approach to a component performance-based material and process development. This allows the identification of component-derived local property requirements, which are converted into tailored material properties. Similar concepts can be found in the literature. Ituarte et al. [38] developed a functional graded material design and manufacturing workflow which includes problem specification, graded structural design, the grading realization and product fabrication. This work focuses on additive manufactured structures of socalled digital materials. Similar approaches of fully integrated design workflows can be found in the field of aminated continuous fiber-reinforced composites [39]. In this context, local property grading for nodular cast iron has been studied by Gebhardt et al. [40] and Ripplinger et al [41]. Both works showed a benefit in terms of increased fatigue strength in the case of high silicone-alloyed nodular cast iron and ferrite graded nodular cast iron. Even though the approach shows high efficiency, it has not been applied to dual-phase steel, nor to crash relevant structural automotive components, to the best of the authors' knowledge.

In this paper, the above-mentioned approach of a component performance-based material and process development is demonstrated on property-graded crash boxes. Here, energy absorption is taken as the main measure for the assessment of the crash box performance. The aim is to increase the energy absorption without endangering the progressive buckling of the crash box by local adjustment of the material properties. Using finite element models, highly stressed regions in the crash box were identified and artificial material cards were assigned locally in order to optimize the energy absorption of the crash box. With this approach, local property requirements were defined. Isothermal-heat-treatment investigations were afterward used to determine information regarding holding time and temperature that allows fulfilling the previously identified mechanical property requirements. Using a process-adapted heat treatment approach, process parameters leading to the desired holding time and temperature were then determined and applied on crash boxes, which were tested quasi-statically afterward. Furthermore, finite element analysis was used to investigate the crushing behavior of the crash boxes. Thereby, the effects of different material behaviors on crash box features such as peak force 
were studied. Furthermore, finite element analysis was used to identify the advantages of local grading over the homogenous heat treatment of the entire crash box regarding the progressive-buckling behavior of it. In comparison to previous studies, current work contains the following novelties:

- implementing a new design approach, from a material focused structural design approach to a component performance-based material and process development;

- identification of component-derived local property requirements, which can be converted into tailored material properties;

- comparison of different local heat treatment strategies on enhancing the crash box energyabsorption;

- definition of advantages and limitations of property-graded crash boxes.

\section{Materials and Methods}

\subsection{Material}

In this study, a cold-rolled DP600 steel with a material thickness of $1.5 \mathrm{~mm}$ was investigated. The chemical composition of the material is displayed in Table 1. As part of the 2nd Gen. Advanced High Strength Steels (AHSS), dual-phase (DP) steels are characterized by their good combination of strength and ductility, which makes them attractive for crash components in the automotive industry. This mechanical property profile of DP steels is attributed to the ferritic-martensitic microstructure. Depending on the hard to soft phase ratio the mechanical properties can be designed. The investigated DP600 steel features a microstructure containing 9.1 $\%$ martensite and $88.9 \%$ ferrite.

Table 1: Chemical composition of DP600 steel, in mass \%.

\begin{tabular}{ccccccccc}
\hline $\mathbf{C}$ & $\mathbf{S i}$ & $\mathbf{M n}$ & $\mathbf{P}$ & $\mathbf{C u}$ & $\mathbf{C r}$ & $\mathbf{M o}$ & $\mathbf{N i}$ & $\mathbf{N}$ \\
\hline 0.113 & 0.390 & 1.38 & 0.0167 & 0.0152 & 0.179 & 0.0515 & 0.0198 & 0.00001 \\
\hline
\end{tabular}

Tensile properties of the DP600 steel were determined following the standard DIN EN ISO 6892-1 using a tensile specimen with a gauge length of $20 \mathrm{~mm}$. According to the tensile test, a yield strength (YS) of 391 $\mathrm{MPa}$, ultimate tensile strength (UTS) of $705 \mathrm{MPa}$, and total elongation (TE) of $31.3 \%$ were extracted. The stress-strain curve and the microstructure of the DP600 are shown in Figure 1.

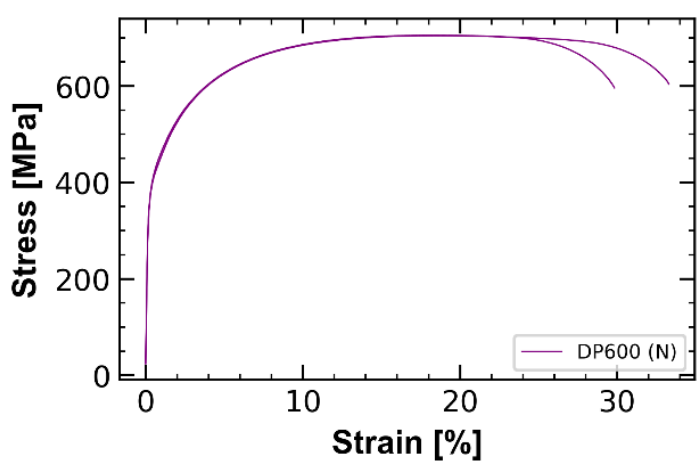

(a)

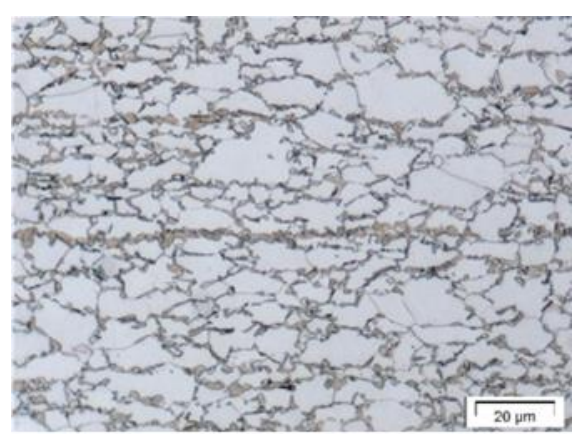

(b)

Figure 1: (a) Stress-strain curve; (b) Microstructure of DP600.

\section{2}

\subsection{Identification of local property requirements using a component-driven approach}

In the present work, a novel methodical approach for integrative material, process, and component design are presented using the example of a thin-walled crash box. This approach aims to demonstrate the potential of a component-driven material and process design in order to increase the energy absorption potential of a crash box. Unlike conventional component design, where global homogenous material properties are defined, this approach first derives required local material properties on the component level by a preliminary analysis that combines FEM simulations with artificial material cards and analytical progressive buckling conditions (1). The experimental fulfillment of these material requirements within the constraints of the applied process 
technology (e.g., short holding times) is investigated by selected, isothermal heat treatments of the base material DP600 in a salt bath. This type of heat treatment is further called isothermal heat treatment. The following material characterization, including microstructural and mechanical investigations, enables the identification of functional relationships between heat treatment process parameters and resulting mechanical properties (2). In order to transfer the outcomes of isothermal heat treatments to a locally applicable heat treatment process, further experiments to define cooling rates and process-specific boundary conditions (e.g., critical cooling rates) are performed. Based on this information, the crash box is locally heat-treated with a moving heat source to adjust the material properties in the required regions, identified in step (1) of this approach. In the following, this type of heat treatment is called process-adapted heat treatment. This processing enables high flexibility considering the location and size of the heat-treated region and thus on the local properties. In the following heat treatment patterns are defined either as line heat treatment or combinations of single spot heat treatments using different spot densities and orientations. To assess the different heat treatment strategies, tensile test specimens were processed by different heat treatment patterns and subsequently tested under quasi-static conditions. The same patterns were applied locally to the corners of the crash boxes (3). The locally heat-treated and reference components were then experimentally tested under axial compression. Based on the forcedisplacement curves, the energy absorption can be derived. Further FE simulations were carried out to assess the performance of isothermal heat-treated crash boxes (4). A Schematic process map of the component-driven approach is shown in Figure 2.

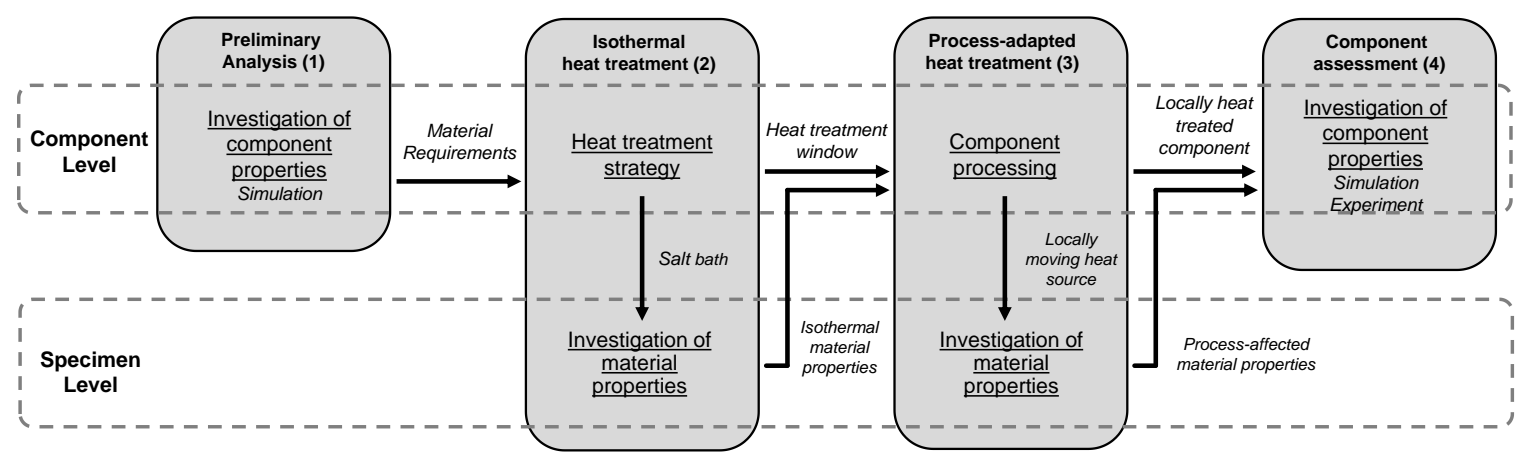

Figure 2: Schematic process map of the component-driven approach.

\section{1}

162

163

164

165

166

167

168

169

170

171

172

173

174

175

176

177

178

\subsection{Crash boxes under axial loading}

To carry out and validate the abovementioned method, both experimental and numerical compression tests on crash boxes are required. These tests were used as a basis for formulating local-material-property requirements to improve the component performance. The crash box specimens were manufactured from DP600 steel, which was characterized in section 2.1. The crash boxes are manufactured by arc welding of two u-shape profiles, which were bent from the DP600 steel sheets. Thus, the weld seams are located in the middle of the side faces. Dimensions of the manufactured crash boxes are $40 \mathrm{~mm}$ x $40 \mathrm{~mm}$ x $200 \mathrm{~mm}$ and the thickness is $2 \mathrm{~mm}$ (Figure 4 (a)).

Even though the normal function of the crash boxes is under dynamic loadings, such as collisions, it is enlightening to first investigate the crash box behavior under a quasi-static load. Moreover, most of the vehicle collisions are in low velocities, about $40 \mathrm{~m} / \mathrm{s}$ at most, and the influence of the stress-wave speed on the crash box behavior during an impact weakens as the impact velocity decreases [42]. As a reasonable simplification, the axial impact behavior of tubes with velocities up to tens of meters per second, for metal tubes, is taken as quasi-static in the literature [12]. Therefore, in this study quasi-static tests were carried out as well for experimental investigation of the energy absorption of the heat-treated crash boxes and also to validate the numerical simulation of the crash box. The specimens were painted with a stochastic pattern to investigate the local strains by digital image correlation (DIC), Aramis GOM. The mechanical tests of the investigated crash boxes were performed by a servo-hydraulic testing machine, Instron 8804 . The sampling frequency was set at $100 \mathrm{~Hz}$. Force signal was correlated with DIC data (sampling frequency of $4 \mathrm{~Hz}$ ) to extract local strains at certain load points of interest during the test. The compression load was applied via a load stamp with a displacement rate of $30 \mathrm{~mm} / \mathrm{min}$ until the crash box is bottomed out. The experimental setup is shown in Figure 3 . 


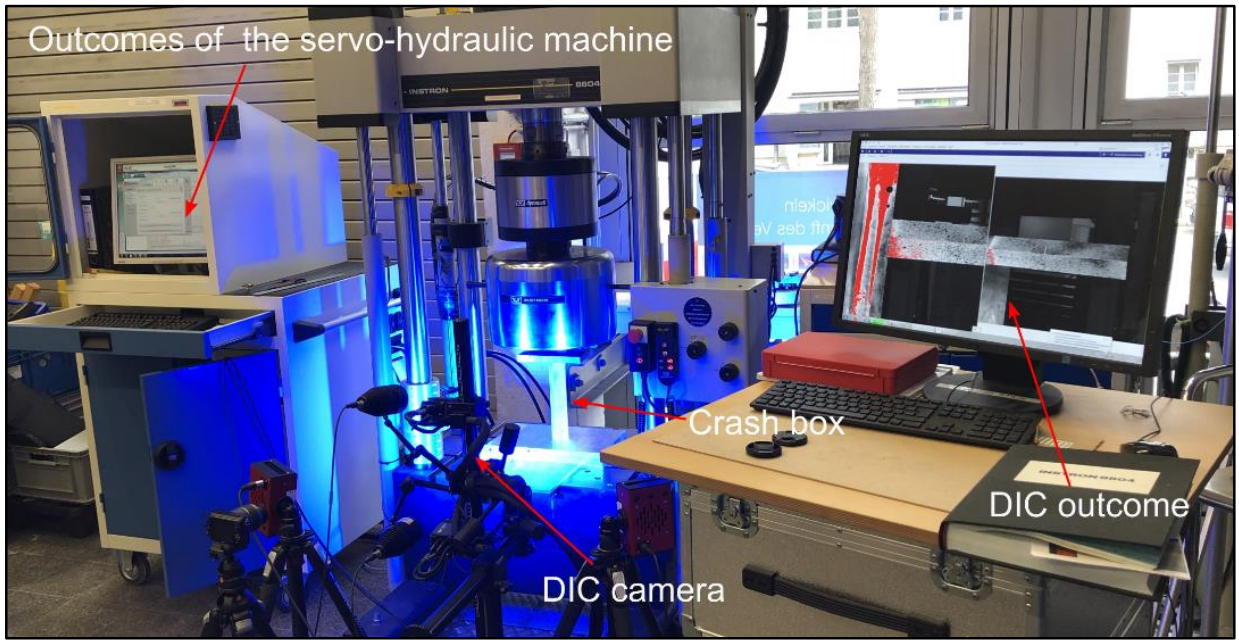

Figure 3: The experimental setup for quasi-static compression of the crash box. DIC method was used for investigating the local strains.

The numerical simulations of the crash boxes were performed using Abaqus commercial software. By considering the symmetry of the crash box and also the symmetry of its crushed form, half of the crash box was simulated. 4-node doubly-curved shell elements with full integration were used for meshing the crash box. By performing a mesh convergence study, a $1.25 \mathrm{~mm}$ mesh size was chosen for the meshing. On the tested crash boxes, there was not any imperfection made deliberately; however, the production phase could not be perfect. Therefore implementing a small imperfection on the FE model can result in more realistic results [43]. Thus, a small imperfection with $0.1 \mathrm{~mm}$ deflection was applied on the second fold region of the crash box (see Figure 4 (b)). The fold region can be located by calculating the fold length of the crash box, as a progressively buckled crash box has a specific fold length. The fold length means the length of the crash box that contributes to a local fold creation and it can be extracted analytically or experimentally, by dividing the crash box length by the number of the folds produced along it $[17,44,45]$. The material card of the DP600 steel was applied to the model. The flow curve was derived from the previously discussed quasi-static tensile tests of the DP600 steel. The equivalent plastic strain value in the simulated crash box can go beyond the strain at the necking point extracted by the one-dimensional tensile test [46]. Thus, the extracted flow-curve was extrapolated using Voce hardening function,

$$
\sigma_{\mathrm{y}}\left(\varepsilon_{\mathrm{p}}\right)=K_{0}+Q\left(1-e^{-b \varepsilon_{\mathrm{p}}}\right)
$$

where $\sigma_{\mathrm{y}}\left(\varepsilon_{\mathrm{p}}\right)$ donates the stress as a function of plastic strain, $\mathrm{K}_{0}$ and $\mathrm{Q}$ are material constants and $\mathrm{b}$ is the strain hardening exponent, which were extracted experimentally, based on the tensile test results (see Table 3).

The explicit method can be used for low-speed quasi-static simulations [47]. To reduce the calculation time, it is often useful to use mass-scaling or reduce the analysis time. Both approaches yield similar results for the rate-independent models [48]. The analysis time of $0.3 \mathrm{~s}$ and mass-scaling factor of 4 were considered for the analysis. Even though the mass scaling and the analysis-time reduction are common approaches to decrease computation time, attention should be taken as they can affect the results accuracy $[43,49]$. Therefore the FE results should be analyzed to be sure about the model accuracy. The calculated kinetic energy was insignificant compared to the energy absorbed by the specimen and the load-displacement diagram was not affected remarkably. Furthermore, in order to ensure the simulation accuracy, the model is validated with the experimental results. 


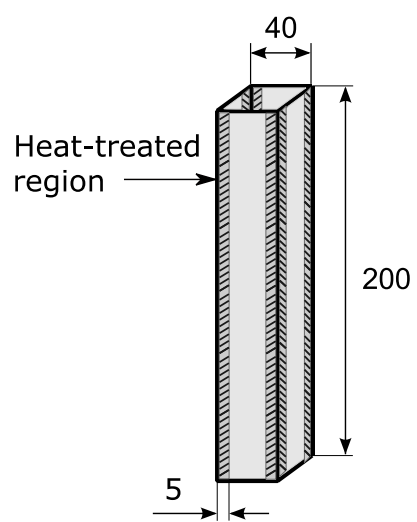

(a)

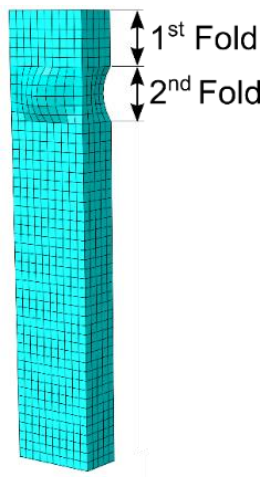

(b)

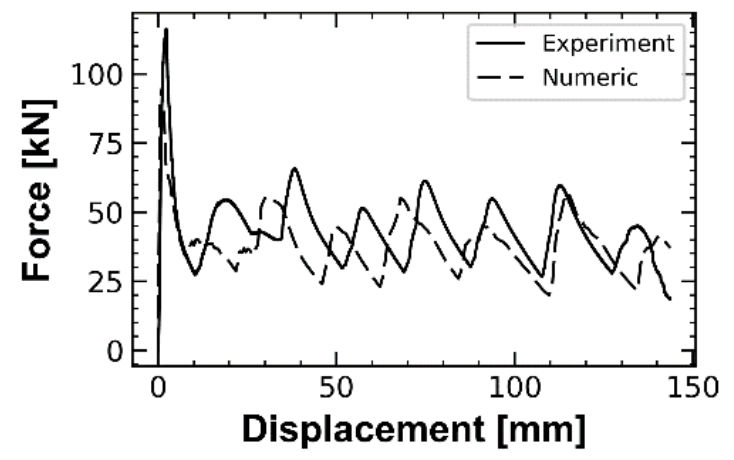

(c)

Figure 4: (a) Dimensions of the tested crash boxes, the thickness of the crash boxes is $2 \mathrm{~mm}$. (b) imperfection on the simulated crash box at the second-fold region (exaggerated); (c) force-displacement diagrams of the experimental test and numerical simulation of DP600 crash box (none heat-treated).

Validating the FE model is crucial in a crash box simulation. FE and experimental results of the compression test on the none heat-treated crash box are presented in Figure 4 (c). Furthermore, Figure 5 shows the comparison of the out-of-plane displacement, in the x-direction, between the FE analysis (a) and the experiment (b) at the peak force moment, captured with DIC method. The extracted peak force is $116 \mathrm{KN}$ (see Figure 4 (c)), this peak force is related to the first fold creation on the tube. The first fold is located at the bottom end of the crash box, both in the FE and experiment. Furthermore, two pre-folds are emerging as well, in the middle and at the top edge of the crash box. Considering the crash box crushed shape and force-displacement diagrams, overall a good agreement could be obtained between the FE model and the experiment. As can be seen in Figure 6, the corners of the crash box face the highest strain. Therefore, increasing strength and ductility of the corners region can improve the energy absorption, which is going to be discussed more in detail in the result section.

The energy absorption of the crash box is defined as the area under the force-displacement curve derived from a component test; whereas, the material's energy dissipation in homogeneous uniaxial deformation (dissipation parameter) is defined as the area under its stress-strain curve extracted by tensile tests and can be seen as the absorbed energy per unit volume. The energy absorption $\mathrm{E}(\mathrm{kJ})$ and the so-called dissipation parameter, D (MPa), describing the combined strength and ductility effect up to the UTS can be calculated as:

$$
E=\int F(\delta) d \delta
$$

$$
D=\int \sigma(\varepsilon) d \varepsilon,
$$


where $\mathrm{F}$ represents the force, $\delta$ the displacement, $\sigma$ the stress and $\varepsilon$ the plastic strain, respectively. In some resources [50], the dissipation parameter is named modulus of toughness when the upper bound of the integration is the fracture strain of the material.
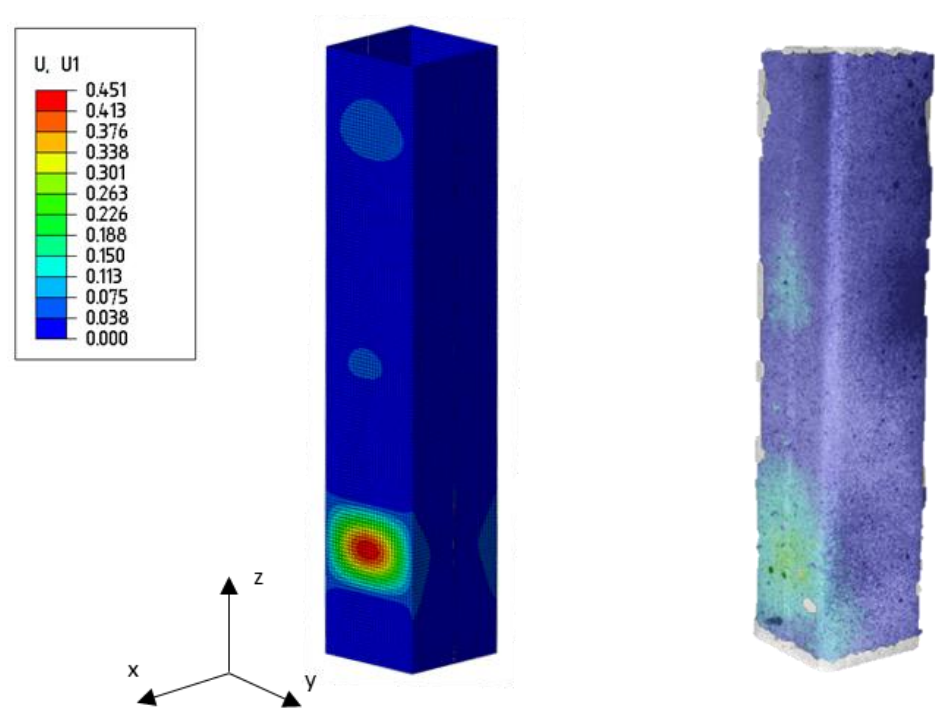

Figure 5: Comparison of the out-of-plane displacement in the x-direction (mm) for peak force between FE analysis (left) and experiment (right) captured with DIC method.

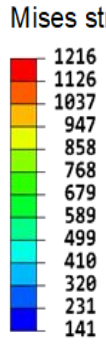

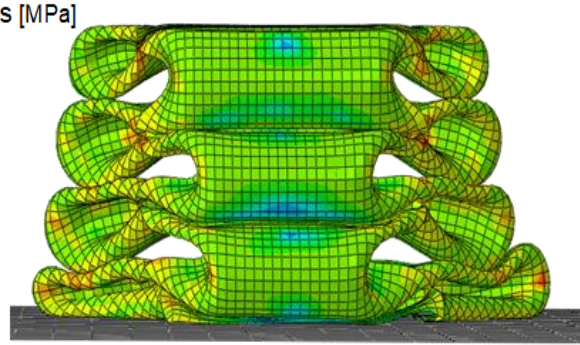

(a)

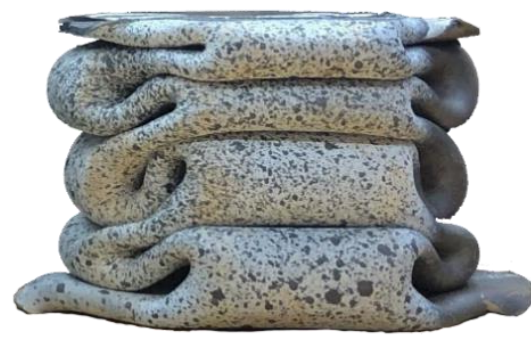

(b)

Figure 6: (a) Validated FE mode; (b) experimental test result of the crash box with DP600 steel material behavior.

\subsection{Progressive buckling and corner-strengthening of a crash box}

Progressive buckling is a prerequisite for the crash box function. A progressive buckling results in local folds production along the crash box length. Plastic deformation is the main energy-absorption mechanism of a crash box and just by a progressive buckling considerable portion of the crash box deforms plastically. Progressive buckling is also named stable deformation under axial loading. A crash box has a progressive behavior when its side plates buckle plastically [6,51]. A crash box can be considered as four connected plates, and critical buckling stress of a plate can be calculated as

$$
\sigma_{c r}=k \frac{\pi^{2} E}{12\left(1-v^{2}\right)}\left(\frac{t}{b}\right)^{2}
$$

where $\mathrm{E}$ is Young modulus, $v$ Poisson's ratio, $\mathrm{k}$ buckling coefficient, $\mathrm{b}$ width and thickness of the plate respectively [52,53]. Based on the dimensions of the plates, the boundary condition of the crash box plates was considered simply supported [54]. Besides the plastic bucking necessity, it was shown in [6] that a crash box 
cannot buckle progressively when the length of the local folds is higher than the crash box width. Therefore, the maximum length of a plate that contributes to a local fold production is the same as the crash box width, see Figure 7. In order to have a plastic buckling, the critical buckling stress of this plate should be beyond the yield stress of the material, $\sigma_{y i e l d}<\sigma_{c r}$, which is a necessary condition for the crash box to buckle progressively $[6,51]$.

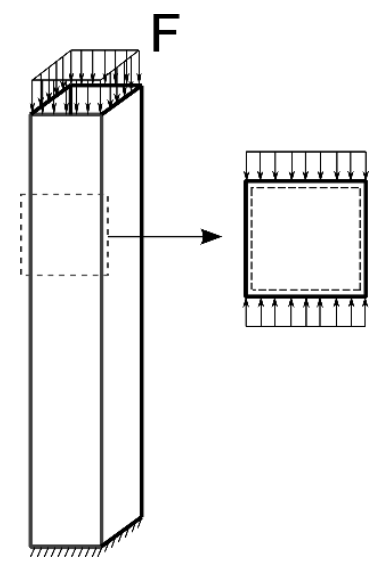

Figure 7: Crash box under compression load $\mathrm{F}$ with the plate region engaged in a local fold.

Crash box corners face the highest deformation by the local folds production. The mechanism of a fold production on a crash box starts with the local buckling of the crash box plates. Plates have a special capability to withstand the axial compression load even after buckling [55] By initiation of the buckling, the mid-side of the crash box plates cannot bear the compression load anymore, and the stress decreases at these regions. However the compressive stress can still increase at the crash box corners owing to the higher rigidity at these regions. Therefore by initiation of the buckling, the stress distribution is not uniformon on the cross section any more. By further loading, crash box corners buckles as well, which is known as crippling, and local folds are produced along the crash box. Production of these local folds results in the creation of the sharp curves and high plastic deformation at the corners, which results consequently in high energy absorption at these regions. Thus, the corners play an important role in the energy absorption of a crash box. High-stress concentration at the crash box corners can be seen in the FE results as well, see Figure 6.

Due to the high importance of the crash box corners in energy absorption, corner strengthening can enhance energy absorption significantly. In this paper the effect of corner strengthening on crash box energy absorption was studied experimentally and numerically, using the validated FE model. A parametric study was conducted to study the effect of different corner strengths. The higher strength material properties were applied on crash box corners, as depicted in Figure 4 (a). Results of these simulations were compared regarding the energy absorption and also peak force of the crash box in the result section. Furthermore, heat-treatment processes on DP600 steel were studied in order to increase the strength at the crash box corners as indicated by the computations.

\subsection{Heat treatments and characterization methods}

The heat treatments to examine suitable strategies to fulfill property requirements were carried out in a salt bath. The material was isothermally heat-treated for one minute at a specific holding temperature, which was ranged from $750{ }^{\circ} \mathrm{C}$ to $950{ }^{\circ} \mathrm{C}$, before quenching in oil. These heat treatments lead to partial or complete austenitization before quenching, so that microstructural configuration is significantly different from the initial state. For microstructural characterization of the different heat treatment states, the samples were etched with Nital after metallographic preparation. The mechanical properties were determined by Vickers hardness test and tensile test according to DIN EN ISO 6892-1.

To transfer the conditions from the isothermal heat treatment to a process-adapted heat treatment that uses a moving heat source, the phase-transformation behavior of the material is studied by dilatometric investigations. Therefore, continuous cooling curves with different cooling rates that range between 1.6 - 204 $\mathrm{K} / \mathrm{s}$ are measured. The combination of this dilatometric data yields a continuous cooling transformation (CCT) diagram (see Figure 13), which can be used to identify critical cooling rates for the DP600 steel. To minimize 
radiation effects on the measurement, the temperature of the specimen is determined on the inside at a point of heat treatment. The crash box specimens were heat-treated by using a tungsten inert gas arc welding torch. Different process-adapted heat-treatment strategies were applied to identify a suitable pattern for increasing the energy absorption of the crash box. Conrads et al. have shown that the energy absorption of crash boxes can be increased by implementing a wavelike pattern using laser heat treatment [35]. However, the arc welding technique has not been investigated for such application. The application of an arc provides a fast and flexible way of heat treatment without the necessity of additional equipment other than a relatively small power source and a welding torch. Line and spot heat treatment patterns have been chosen, which are easy to implement in an industrial context. Figure 8 depicts the different heat treatment patterns. In the following, it can be distinguished between non-heat-treated $(\mathrm{N})$, line heat-treated $(\mathrm{L})$, spot heat-treated $(\mathrm{S})$ and spot double-dense heat-treated (SDD) patterns. In addition to crash boxes, tensile test samples with similar heat treatment patterns were manufactured to compare material properties resulting from process-adapted heat treatment and isothermal heat treatment. The shape DIN 50125 - H 20 x 120 was chosen for the tensile test samples. In accordance with DIN 6892-1, an elongation speed of $15 \mathrm{~mm} / \mathrm{min}$ was used for these tests.

a) Spot Double Dense Spot

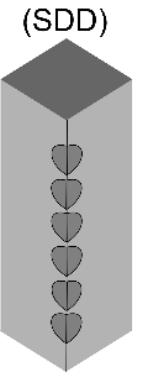

b)

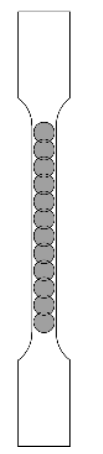

\section{(S)}
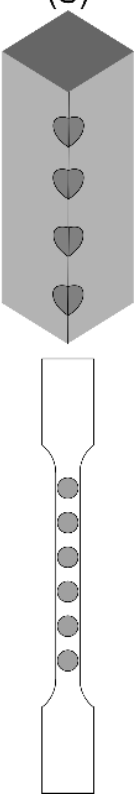

Line
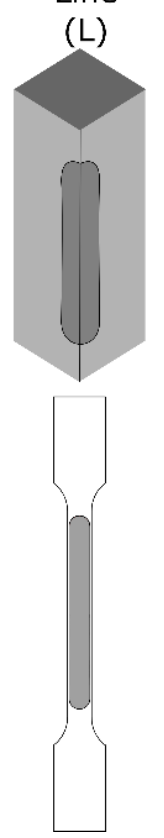

Base material

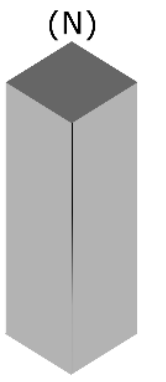

c)
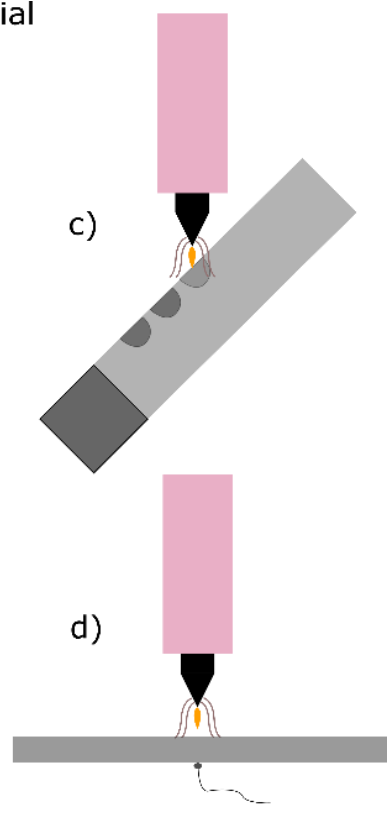

Figure 8: (a) Heat-treatment pattern on the crash box; (b) Heat treatment pattern on the tensile specimen; (c) schematic of heat treatment setup; (d) Indication of the thermoelement positioning.

\section{Results and Discussion}

\subsection{Energy absorption of the corner-strengthened crash box}

The FE-analysis results of the corner-strengthened crash box are provided in this section. As it was discussed, strengthening the crash box corners can improve the crash box energy absorption. A parametric study was conducted and different material cards were applied on the crash box corners in order to study the edge strengthening effect. The DP600 steel has true ultimate stress of $841 \mathrm{MPa}$. Three artificial materials were defined with increased ultimate stress of $1000 \mathrm{MPa}, 1200 \mathrm{MPa}$ and $1400 \mathrm{MPa}$, named U1000, U1200 and U1400 respectively. Except the plasticity parameters, all the other parameters, e.g., Young's modulus and yield stress, of the artificial materials were kept the same as the DP600 steel. The flow curves of the materials were extrapolated using Voce-law. The extrapolated stress-strain curves of the artificial materials and DP600 steel are shown in Figure 10 (a). The extrapolated curves were used for the numerical simulations of the crash box. The artificial materials were applied to $5 \mathrm{~mm}$ wide strips along the crash box corners (Figure 4 (a)). Voce-law parameters, the energy absorption and the peak force of the corner-strengthened crash boxes are shown in Table 3. The force-displacement diagram of the U1400 corner-strengthened crash box is compared with the DP600 
crash box in Figure 10 (b). The force-displacement diagram of the other strengthened crash boxes are located between the shown graphs. As it is obvious in the diagrams; even though the energy absorption of the strengthened crash box is increased considerably, the peak force is almost the same as the non-heat-treated DP 600 crash box. According to the FE results, by applying U1400 locally to the corner of the crash box, the energy absorption is increased up to $32 \%$ without any change in structural and folding behavior. This increase is correlated to the improved balance of strength and ductility caused by the increased UTS. Thus, a component motivated local-material requirement can be defined as follows:

\section{The corners of a crash box should have a higher strength level compared to the base material}

However, in common steels an increase in strength goes along with a decrease in ductility which subsequentially leads to an earlier failure event. Therefore, a local strength increase of a crash box might be limited by the possibility of an early local fracture. Even though large cracks during the fold creation should be avoided, Liu et al. showed that the influence of local fracture appearance after folding has a negligible effect on the energy absorption of a crash box [10].

As it was discussed, an improved performance can be achieved by grading the material properties on the crash box. A low yield stress at mid-plate region results in progressive buckling of the crash box and a high stiffness at the corners increases its energy absorption. However, a minimum required ductility at the corners should also be considered in the design to prevent large cracks formation, as the highest deformation takes places at these regions. This minimum ductility acts as a boundary condition for the design. The radar chart of Figure 9 depicts the design requirements for corner-strengthened crash boxes.
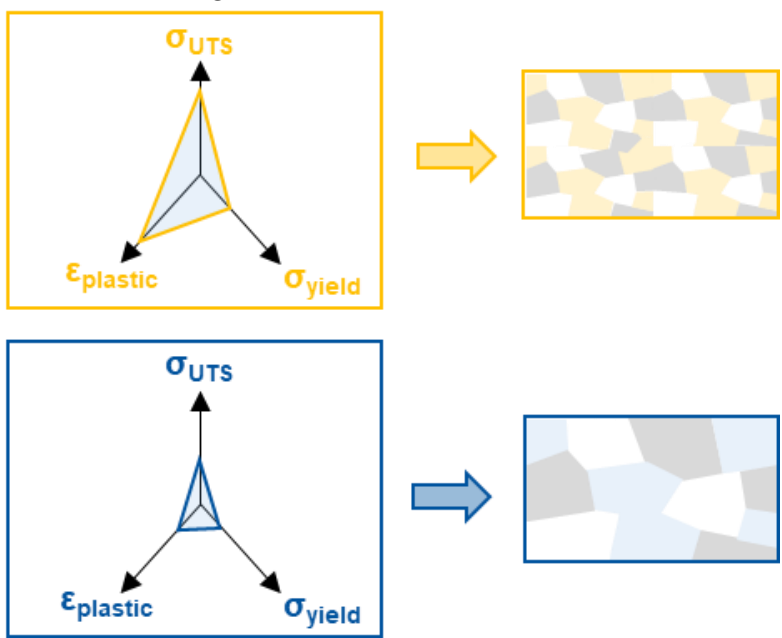

Figure 9: Requirement definition of the corner strengthened crash box (depicted as a radar chart) and corresponding microstructures (schematic).

\subsection{Isothermal heat treatments}

The component simulations showed that an increase of strength at the corners of the crash box leads to an improvement of the overall crash box performance, see Figure 10. In order to fulfill the proposed requirement and achieve similar improvements in the experimental component tests, the local microstructure, and thus the mechanical property profile of DP600 steel in the crash box corners needs to be adapted. The suitable microstructure adjustment can be achieved by isothermal heat treatment. During this heat treatment, the material is held at a temperature within the austenite-ferrite or fully austenitic range before it is quenched to room temperature. The rapid cooling transforms the austenite into martensite, resulting in a ferritic-martensitic or fully-martensitic microstructure whose phase fraction composition, morphology, grain size, and local chemical composition depend on the isothermal heat treatment temperature. The choice of a suitable isothermal holding temperature is therefore important to fulfill the requirements from the component simulations. To propose a suitable process window for the process-adapted heat treatment, isothermal heat treatments at different temperatures were carried out. In Figure 11 (b) it can be seen that the martensite (M) phase fraction, determined in light optical measurements, increases between $775{ }^{\circ} \mathrm{C}$ and $850{ }^{\circ} \mathrm{C}$ from $26 \%$ to $98 \%$. At the same time, the amount of ferrite $(\mathrm{F})$ in the microstructure decreases proportionally. At higher holding temperatures, the 
microstructure remains similar and the martensite fraction shows a low variation of 1-2 \%. A similar trend can be found for the hardness profile. The hardness increases with raising the temperature from $235 \mathrm{HV}$ up to 413 $\mathrm{HV}$ where a plateau is reached. The constant hardness and the high martensite content above a holding temperature of $850^{\circ} \mathrm{C}$ indicate that Ac3 temperature has been reached. This hypothesis was verified by dilatometry studies. According to the investigations, the Ac3 temperature lies at $837^{\circ} \mathrm{C}$.

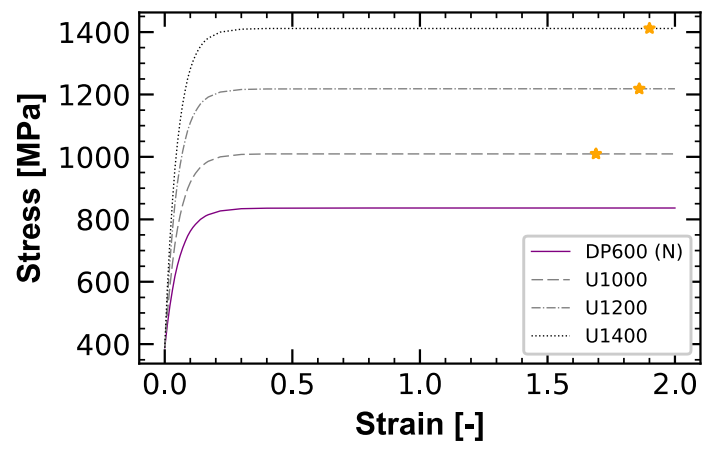

(a)

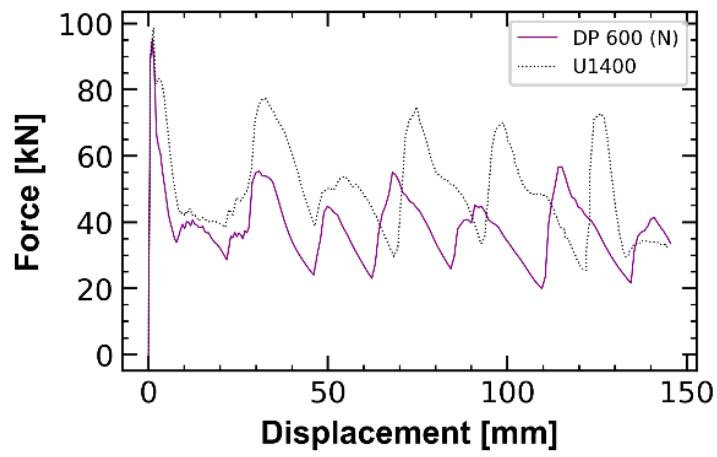

(b)

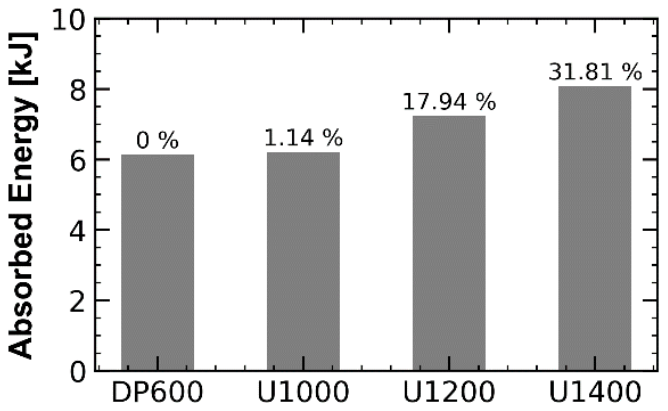

(c)

Figure 10: (a) Extrapolated DP600 steel and the artificial flow curves defined for corner-strengthening of the crash box; including maximum PEEQ values experienced in the simulation (stars), (b) FE results of DP600 crash box and U1400-strengthened crash box. Force-displacement diagrams of other strengthened crash boxes are located between the shown graphs; (c) Absolute and proportional (compared to DP600) energy absorption for each artificial material

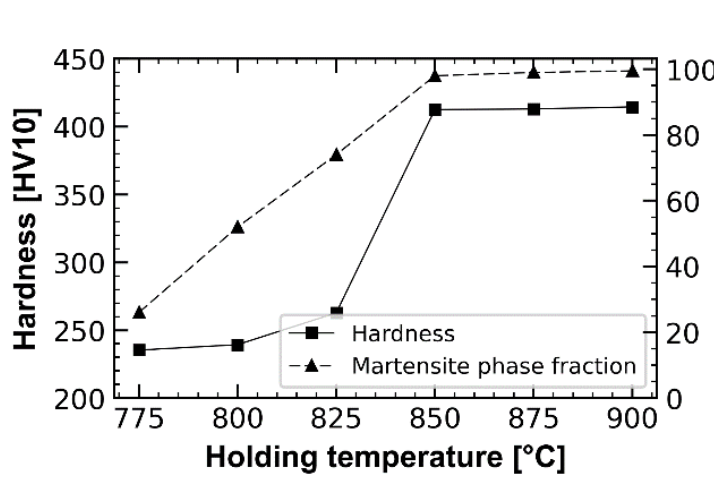

(a)
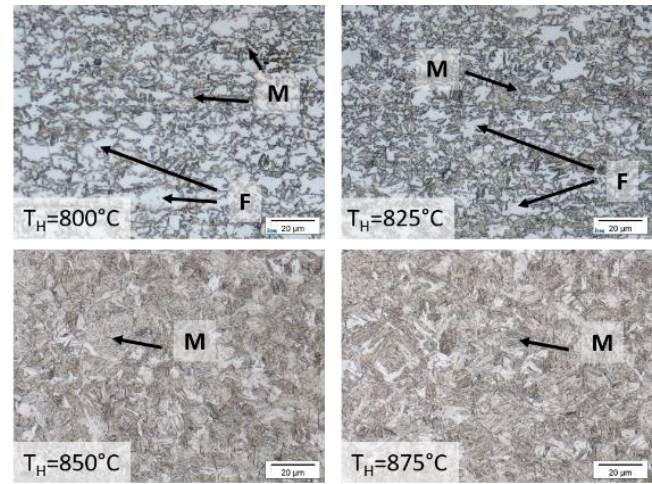

(b)

Figure 11: (a) Influence of the isothermal holding temperature on the hardness and martensite phase fraction of heat-treated DP600; (b) Light optical microscopy images of the heat-treated DP600, natal etching.

Based on the previous results, tensile test specimens were processed at a holding temperature ranging from $800{ }^{\circ} \mathrm{C}$ to $875^{\circ} \mathrm{C}$. Figure 12 shows the stress-strain curves of the heat-treated DP600 specimens. It can be seen that yield strength and ultimate tensile strength increase with higher holding temperature, while the uniform 
and total elongation decrease. However, the stress-strain curves at a holding temperature of $850{ }^{\circ} \mathrm{C}$ and $875{ }^{\circ} \mathrm{C}$ show similar behavior, which correlates to the microstructural and hardness findings.

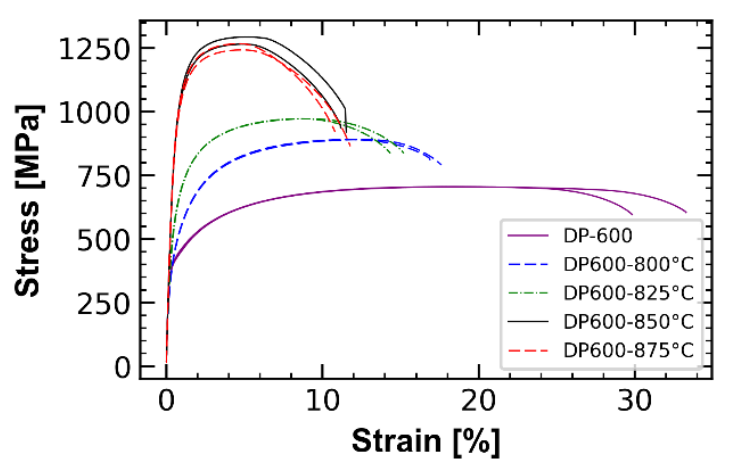

Figure 12: Stress-strain curves of heat-treated DP600 samples.

From the tensile test curves, it is clear to see that the strength level required by the component simulation, i.e., U1400, cannot be achieved completely, but at least the desired UTS level can be approximated by an isothermal heat treatment at $850-875^{\circ} \mathrm{C}$. Thus, a reasonable process window could be defined for the processadapted heat treatment:

According to isothermal heat treatment, the local property requirements can best be met by isothermal heat treatment of DP600 steel for $60 \mathrm{~s}$ at a holding temperature of $850^{\circ} \mathrm{C}$.

\subsection{Process-adapted heat treatments}

The transfer of the process window determined by isothermal heat treatment in salt baths to process-adapted heat treatment using a moving heat source requires additional investigations. To investigate the phasetransformation behavior of the DP600 steel, dilatometric measurements under continuous cooling conditions were conducted. The results are shown in Figure 13. Based on the CCT diagram, a feasible process window to achieve the desired mechanical properties can be determined. In accordance with this study, local heat treatment should achieve temperatures above Ac3 for the material to be fully austenitic. The cooling rate after the heating process determines the distribution of austenite, ferrite and martensite. Higher cooling rates lower the transformation temperatures to around $350^{\circ} \mathrm{C}$ and $290^{\circ} \mathrm{C}$ and therefore increase the austenite ferrite ratio.

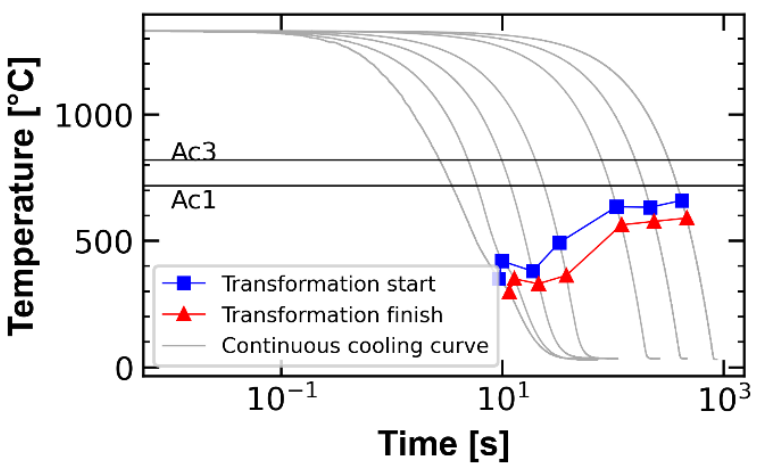

Figure 13: CCT-diagram measured with cooling rates between $200 \mathrm{~K} / \mathrm{s}$ and $2 \mathrm{~K} / \mathrm{s}$.

The parameters for the welding power source were derived by these measurements and chosen as high as possible without creating a weld pool on the surface of the material. For the process-adapted heat treatment of tensile specimens and crash boxes, a welding current of $8 \mathrm{~A}$ and a voltage of 12-15 V were proven to be suitable. The temperature measured during heat treatment is displayed in Figure 14. These results were obtained from the opposite side of the heat source (see Figure 8) to minimize errors introduced by radiation emitted from the arc. Clearly visible is the difference of time exposed to temperatures above $400{ }^{\circ} \mathrm{C}$ for the two different 
configurations "S" (spot) and "L" (line). To achieve the targeted effect of higher UTS the measured temperatures are insufficient because the desired holding temperatures have not been reached. However, due to the highly inhomogeneous nature of the temperature distribution around the arc, it is possible areas even closer to the heat source may have reached higher temperatures than those that were measured on the opposite side of the heat source, so it is likely that the desired temperature was reached. Therefore, the samples treated by a movable heat source might perform similar to those that were heat-treated in salt baths.

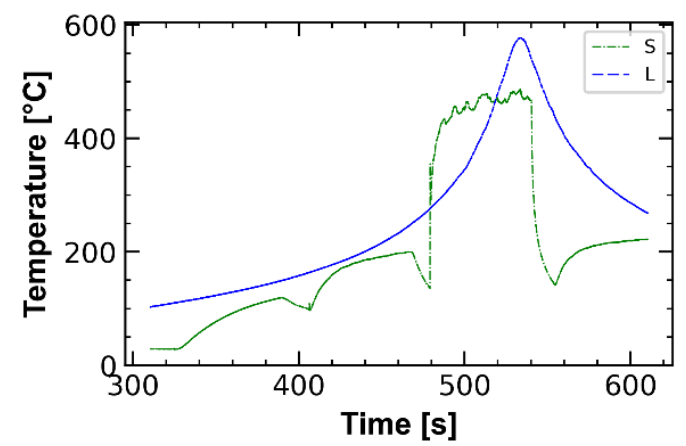

Figure 14: Local temperature experienced during the heat treatment for the two configurations "S" (spot) and "L" (line).

In order to assess the different patterns applied to the crash box depicted in Figure 8, tensile specimens with identical process-adapted heat treatment strategies were produced and tested. These tests were accompanied by a full-field strain measurement using DIC to obtain the difference in local material properties at the location of heat treatment. The results obtained from the analysis of local strains are displayed in Figure 15. There are clear distinctions at the location of local heat treatment in comparison to the untreated areas. The positions are chosen in order to demonstrate the effect of local heat treatment as they display the highest strain in the sample. The point of failure is not evaluated because of the shortcomings of DIC. The speckle pattern is not stable if there is a crack in the sample, therefore the position with the next highest strain was chosen throughout. The spot heat-treated (S) tensile test sample displays a difference of local strain by the factor of two compared with line heat-treated (L) at UTS. The projected raising of the UTS from around $800 \mathrm{MPa}$ to over $1400 \mathrm{MPa}$ is not visible. However, a notable deviation of the balance between strength and ductility up to UTS is visible between the different heat-treated specimens.

(a)

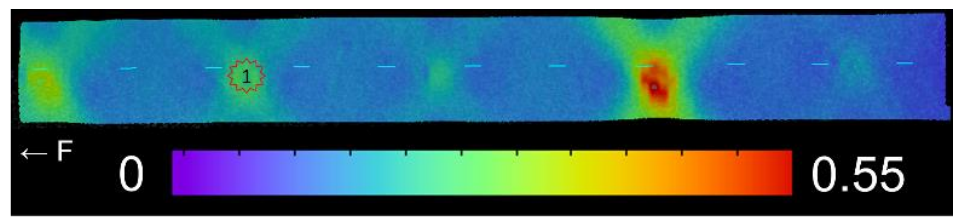

(b)

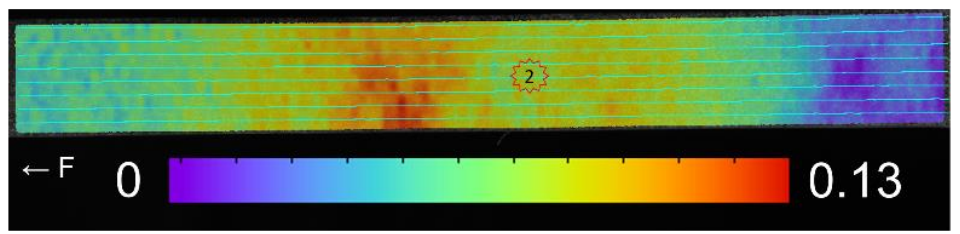

(c)

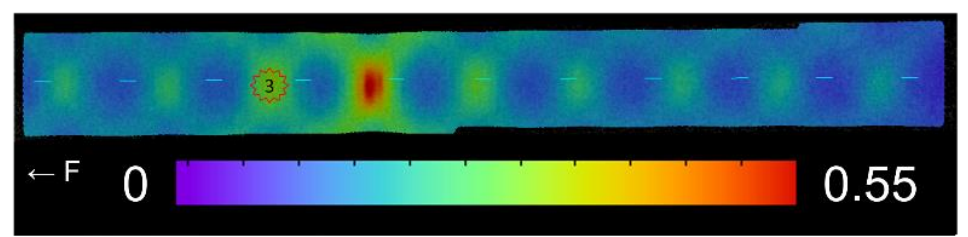




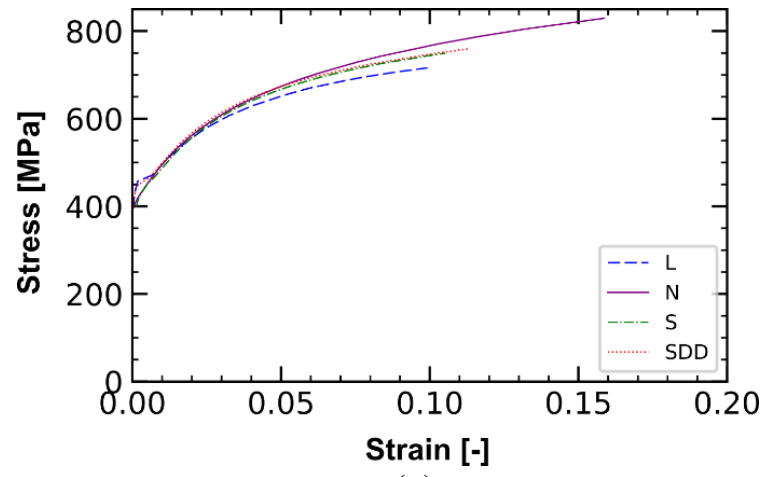

(a)

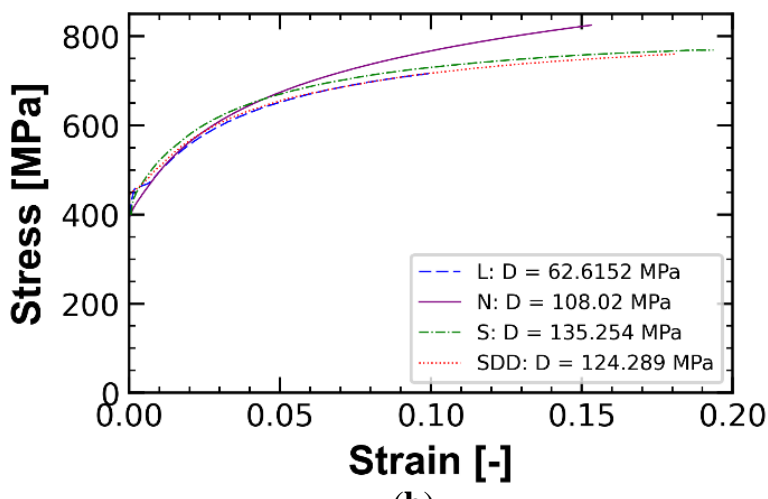

(b)

Figure 16: (a) Global true stress and true strain curve; (b) Local true stress-strain curve of heat-treated tensile specimen at the depicted positions. Dissipation parameters (D) were calculated up to the UTS.

The tensile test results of the different heat-treatment strategies are shown in Figure 16. As plastic deformation is the prevailing mechanism of the energy absorption in the crash boxes, the flow curves were extracted and compared with the flow curve of the base material up to UTS. The material behavior after UTS is highly dependent on the stress state, which in itself depends on factors like geometry and the heat treatment pattern. Therefore, the extent of inference on crash boxes is very limited. The tensile test results show the applied heat treatment processes do not result in a higher UTS. On the contrary, the results show a decrease in UTS for "L" and S. The reduction of UTS is probably due to the huge temperature gradient induced by the arc. However, the resulting property gradient displays an improved ductility and dissipation parameter until UTS for several heat treatments ranging from $\mathrm{T}=62.62 \mathrm{MPa}$ with " $\mathrm{L}$ " heat treatment to $\mathrm{T}=135.25 \mathrm{MPa}$ with " $\mathrm{S}$ " heat treatment, which affect the energy absorption of the crash boxes.

\subsection{Component assessment}

\section{Performance of the process-adapted heat treatment}

The heat-treated crash boxes were tested under quasi-static compression, see Figure 17. The experiment results show that the process-adapted heat treatments do not affect the folding behavior of the crash box considerably. In quasi-static compression of a crash box, the first fold is produced randomly along the crash box, based on its imperfections. Due to the regular folding pattern, crash boxes have a specific fold length, thus based on the first fold location a small deviation in the number of the folds can be seen in the tested crash boxes. In the conducted tests, "S" and "SDD" crash boxes have eight folds, whereas "N" and "L" crash boxes have seven folds; however, some small-size unfolded regions remain at both ends of "N" and "L" crash boxes. Therefore it can be concluded that the applied local heat treatments do not affect the fold length of the crash boxes.

N

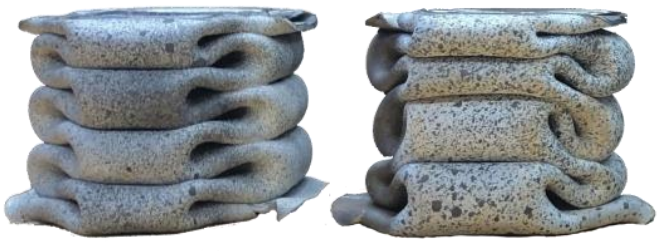

S

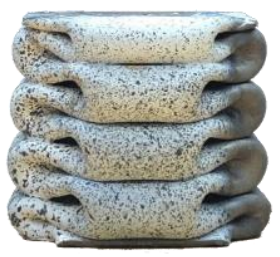

SDD

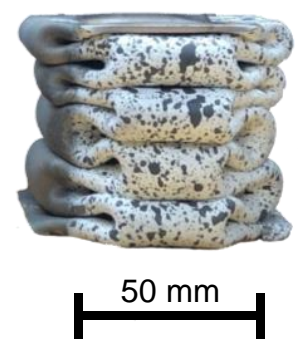

Figure 17: Compression test result of the crash boxes with different heat treatments: non-heat-treated (N), line heat-treated (L) spot heat-treated (S) and spot double-dense heat-treated (SDD).

The resulting force-displacement curves of "N", "L", "S" and "SDD" heat-treated crash boxes and overview of the extracted results are shown in Figure 18 (a) and Table 2 respectively. "N" crash box represents the reference configuration for the comparison. Due to the deviation in the number of the produced folds, absorbed energy over crushing distance diagrams of the crash boxes were considered in extracting energy absorption change of 
them. In order to extract the effect of the local heat treatment on energy absorption of the crash boxes, first energy absorption over crushing distance was extracted using equation (2) for all the crash boxes. Subsequently, the absorbed energy of each crash box was correlated with the reference configuration and a regression line was fitted to the curve. The slope of the fitted line shows the level of the energy-absorption change due to the local heat treatment. An exemplar is shown for "S" crash box in Figure 18. The slope of the fitted line is 1.028, which shows a $2.8 \%$ energy absorption increase compared to the "N" crash box. The energy absorption changes of all the crash boxes were extracted using the same approach. A similar effect to "S" crash box can be seen for the "SDD" crash box as well, which has an energy absorption increase of $2.2 \%$. In contrast, the "L" crash box has an energy absorption decrease of $4 \%$. Obviously, additional factors have resulted in a negative effect on the component performance. The particular metallurgical reasons for this behavior have to be the subject of further studies.

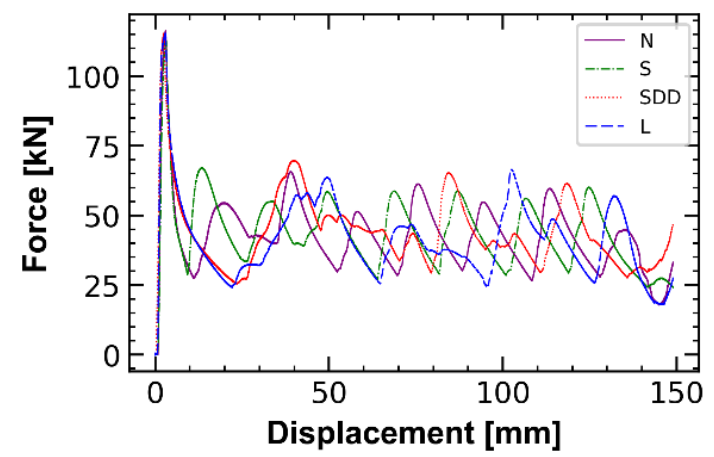

(a)

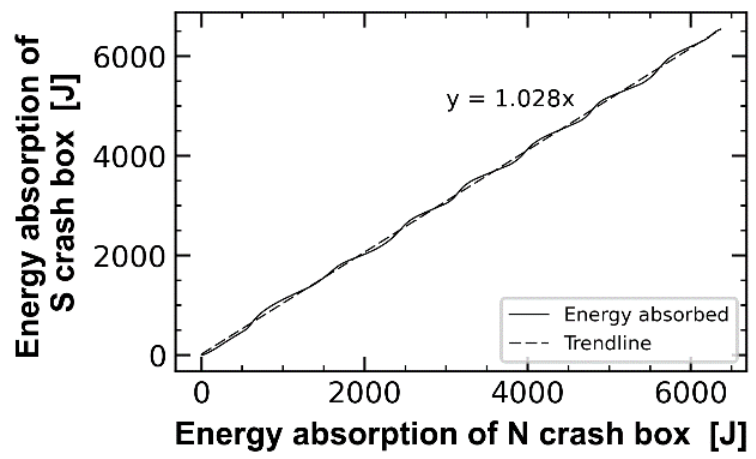

(b)

Figure 18: (a) Force-displacement diagrams of all tested crash boxes; (b) Energy absorption of "S" crash box over energy absorption of "N" crash box with a linear fit.

Table 2: Compression test results of the locally heat-treated crash boxes.

\begin{tabular}{ccccc}
\hline Heat treatment pattern & $\mathbf{N}$ & $\mathbf{L}$ & $\mathbf{S}$ & SDD \\
\hline $\begin{array}{c}\text { Dissipation parameter (MPa) } \\
\text { of corresponding tensile test }\end{array}$ & 108.02 & 65.62 & 135.3 & 124.3 \\
\hline Peak force (kN) & 116.3 & 115.4 & 112.8 & 115.4 \\
\hline $\begin{array}{c}\text { Energy absorption } \\
\text { experiment (kJ) }\end{array}$ & 6.37 & 6.11 & 6.55 & 6.51 \\
\hline $\begin{array}{c}\text { Normalized Energy } \\
\text { Absorption (\%) }\end{array}$ & - & -4.0 & 2.8 & 2.2 \\
\hline
\end{tabular}

In this part, the energy absorption difference of " $\mathrm{S}$ " and "N" crash boxes is compared to have a more robust data evaluation. The difference in energy absorption, $\Delta \mathrm{E}$, between the crash boxes was extracted over the crushing distance, see

Figure 19. Unsynchronized local buckling of the crash boxes results in fluctuation of the $\Delta \mathrm{E}$ curve. Using a linear fit a smoothing of $\Delta \mathrm{E}$ was achieved, and the energy absorption increase, owing to the corner strengthening of the crash box, is obvious during the crushing. It can be seen that the " $\mathrm{S}$ " crash box continuously absorbs more energy than the "N" crash box.

Different process-adapted heat treatments lead to specific energy absorption potentials. According to the global flow curves (see Figure 16) of the process-adapted heat-treated specimens, the highest energy absorption potential could be expected for "N" crash box. Nevertheless, "S" crash box and "SDD" crash box show a higher energy absorption. Thus, the corresponding local material properties that are related to the individual heat treatment patterns should be taken into account. Therefore, the balance of strength and ductility (dissipation parameter in equation 2) is defined as the reference material property for comparing each process-adapted heat treatment. Figure 20 displays the crash box energy absorption over the dissipation parameter for each processadapted heat treatment. The graph indicates a linear correlation between the dissipation parameter and energy absorption. Starting from the reference, "N" crash box, a lower dissipation parameter leads to an energyabsorption decrease, while a higher dissipation parameter results in an increase in energy absorption. The reason for this correlation can be found in the local material properties in the corners of the crash box. Crash boxes " $\mathrm{S}$ " 
and "SDD" show increased early strain hardening without significant reduction of UTS (Figure 16) so that their dissipation parameter is higher compared to the reference crash box "N". In contrast, crash box "L" shows a slightly improved strain hardening at the early stage of yielding, but due to the different thermal conditions compared to "S" and "SDD" crash boxes, UTS is significantly lowered compared to the reference crash box "N". In total, this results in a decreased dissipation parameter, accordingly, the energy absorption is decreased compared to the reference configuration "N". Comparing "S" and "SDD" crash boxes, owing to the interaction of the spots in "SDD" heat-treatment pattern, the dissipation parameter of "SDD" is below "S" pattern, which results in lower energy absorption as well. Likewise, the effect of the dissipation parameter on the crash box energy absorption can be approximated as shown in Figure 20. The presented results serve as a good example to demonstrate that materials design and component design show pronounced interactions that should be considered to establish new lightweight engineering potential.

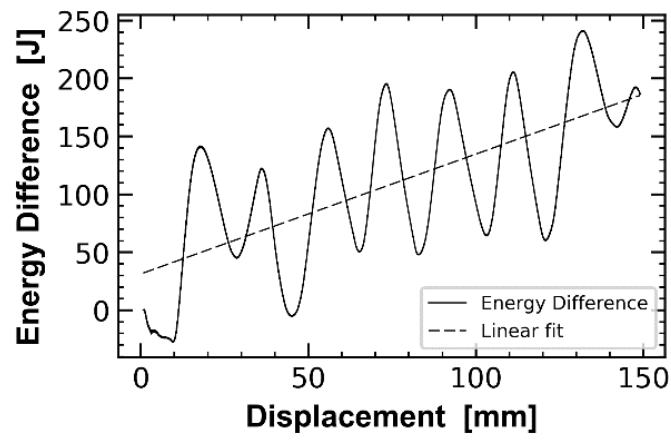

Figure 19. Energy absorption difference between "S" crash box and "N" crash box (reference) over crushing distance. The positive slope of the fitted line shows enhanced energy absorption of the "S" crash box during the crushing.

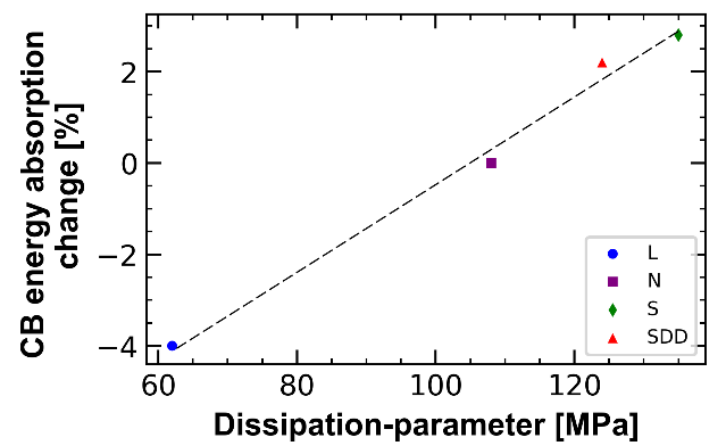

Figure 20 Energy absorption change of the crash boxes due to the dissipation parameter change at the crash box corners. The linear trend indicates the strong influence of corner material properties on overall performance.

\section{Performance of the isothermal heat treatment}

Since the isothermal heat treatment in salt bath was not applied to the crash box, owing to the limitation of the applied process-adapted heat treatments, the component assessment was carried out based on FE analysis. Recommended isothermal heat-treated (ISO-HT) material behavior, discussed in Section 3.2, was applied to the corner of the crash box as described in Figure 7. The simulated crash box shows a 53\% energy-absorption increase compared to the DP600 reference model, which is much more than that of the U1400 strengthened crash box, i.e., 32\%, see Table 3. Comparing the energy absorption of the U1400 and ISO-HT strengthened crash boxes, even though the ISO-HT steel has lower ultimate stress than U1400, its energy absorption is higher. The higher energy absorption is related to the higher strain-hardening in the early phase of yielding in ISO-HT. The high energy absorption can be explained by considering that the significant portion of the crash box is deformed plastically at relatively small equivalent-plastic strains, and the ISO-HT affects this portion much more than the U1400. However, the strong hardening at the beginning of the ISO-HT flow curve results in an 
crash box, peak force of U1000, U1200 and U1400 strengthened crash boxes are almost the same as the DP600 reference model (Table 3). The sharp increase of the peak force can be explained by analyzing the fold-creation mechanism. In a plastically buckled crash box, by increasing the stress beyond the yield point, material stiffness, $E$, decreases significantly, which results in local buckling and fold creation on the crash box, see equation (4). Therefore the fold is created at relatively small plastic strain values. Thus, both the yield stress and hardening behavior of the material in the low strain region affect the peak force. For a better investigation, a new material card, named U1400Y952, was defined with the same yield stress as ISO-HT and higher ultimate stress of 1400 MPa. The new material has a lower hardening behavior than ISO-HT at low strain values, see Figure 21 (a). Comparing the crash boxes strengthened with ISO-HT and U1400Y952 material cards; even though both absorb almost the same amount of energy, U1400Y952 has a 5.3\% lower peak force due to a lower hardening behavior, see Table 3 and Figure 21 (b). In sum, corner strengthening of crash boxes using a material behavior with a low yield stress, low hardening and high ultimate stress enhances the crash box energy absorption and prevents the destructive increase of the peak force.

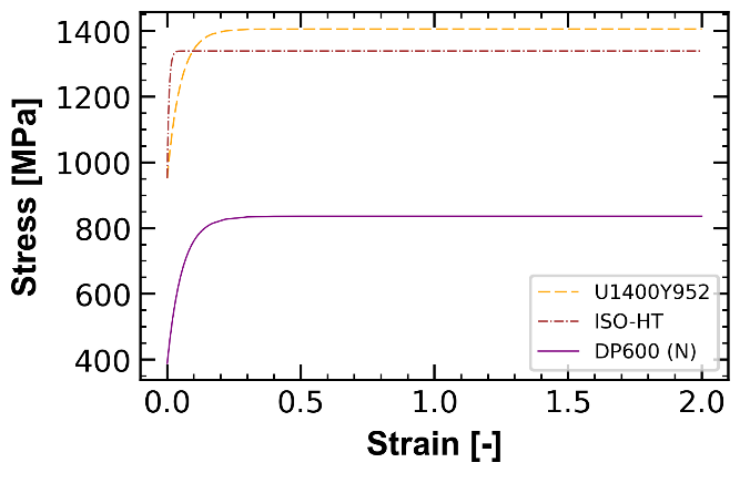

(a)

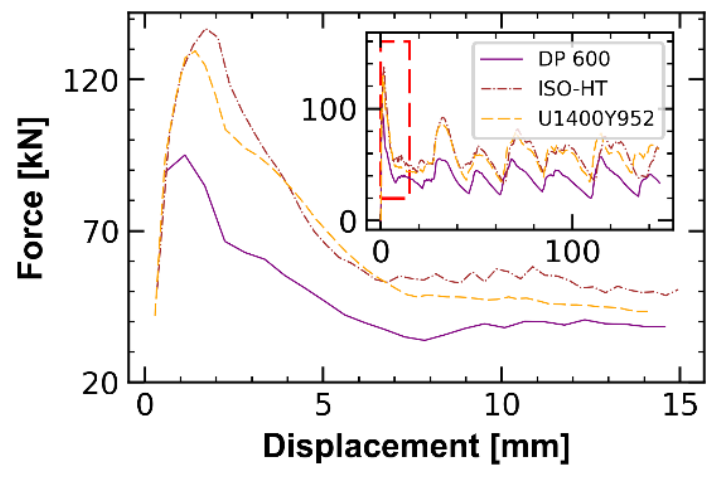

(b)

Figure 21: (a) Material cards used for FE simulation; (b) FE results of DP600, ISO-HT strengthened and U1400Y952 strengthened crash boxes.

Table 3: Extracted parameters of the Voce hardening functions for extrapolating the materials and energy absorption value extracted using the validated FE model.

\begin{tabular}{cccccccc}
\hline Material & $\begin{array}{c}\mathrm{K}_{0} \\
(\mathrm{MPa})\end{array}$ & $\begin{array}{c}\mathrm{Q} \\
(\mathrm{MPa})\end{array}$ & $\begin{array}{c}\mathrm{b} \\
(-)\end{array}$ & $\begin{array}{c}\mathrm{UTS} \\
(\mathrm{MPa})\end{array}$ & $\begin{array}{c}\mathrm{F}_{\mathrm{peak}} \\
(\mathrm{kN})\end{array}$ & $\begin{array}{c}\text { Energy Absorption } \\
(\mathrm{kJ})\end{array}$ & $\begin{array}{c}\text { Normalized Energy- } \\
\text { Absorption Change } \\
(\%)\end{array}$ \\
\hline DP600 & 388.7 & 447.4 & 17.9 & 841 & 95 & 6.13 & - \\
\hline U1000 & 388.7 & 621 & 19.1 & 1000 & 95 & 6.2 & 1.14 \\
\hline U1200 & 388.7 & 829.3 & 20.3 & 1200 & 97.5 & 7.23 & 31.81 \\
\hline U1400 & 388.7 & 1023 & 20.6 & 1400 & 98.5 & 8.08 & 52.69 \\
\hline ISO-HT & 952 & 387.1 & 146.1 & 1359 & 137 & 9.36 & 53.67 \\
\hline
\end{tabular}

Benefits of corner-strengthening on crash box progressive-buckling behavior

Enhancing the energy absorption capacity of a crash box should not endanger its progressive buckling. Using equation (4) elastic buckling stress of the experimentally tested crash box can be calculated as $1888 \mathrm{MPa}$. The calculated buckling stress is higher than the yield stress of the DP600 steel, i.e., $389 \mathrm{MPa}$, and it is expected that the crash box buckles progressively, which is confirmed by the experimental results (Figure 17). In order to explore the advantages of the corner-strengthening of the crash box over homogenous heat treatment of it, three simulations were conducted using the validated FE model. By decreasing the crash box thickness to $1 \mathrm{~mm}$, the critical buckling stress of the crash box decreases to $451 \mathrm{MPa}$. The buckling stress is below the yield stress of the ISO-HT DP600 steel, i.e., $952 \mathrm{MPa}$. However, the buckling stress is still beyond the yield stress of the DP600 steel. Two simulations were conducted on crash boxes using the DP600 steel and ISO-HT material cards. The results are shown in Figure 22 (a) and (c). As it was predicted, the crash box made by the ISO-HT steel buckles unprogressively, but the crash box made by DP600 steel buckles progressively. For longer crash boxes, 
this unprogressive behavior can result in global bending of the crash box, which prevents the energy absorption process. A corner-strengthened crash box was simulated in addition to the previous simulations. Material properties of the DP600 steel were used for the mid-plate region and ISO-HT material card was applied to the corners (see Figure 21 (a)). The corner-strengthened crash box shows progressive behavior and produces the same number of the folds as DP 600 crash box, see Figure 22 (b). Thus, by corner-strengthening the crash boxes, the energy absorption can be increased without any critical change in the crushing behavior.

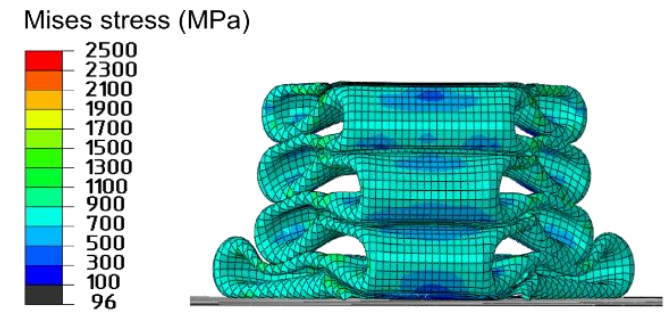

(a)

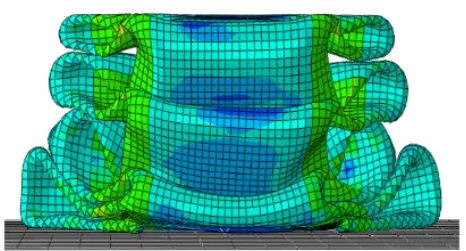

(b)

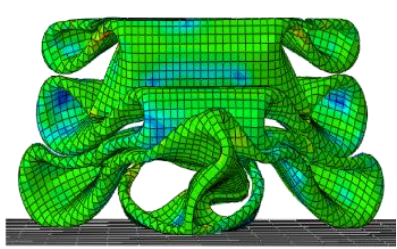

(c)

Figure 22: Crushed crash boxes (1mm thickness) of (a) DP600 steel; (b) Homogenous heat-treated using ISOHT; (c) ISO-HT-strengthened crash box.

\section{Evaluation of component-driven approach in the context of other methodologies}

An increase in component performance can be achieved through either material, process or design techniques [23,26,34]. In most cases, material-technical approaches to enhance the component performance first obtain improved mechanical material properties by means of heat treatment strategies, which then positively influence the component behavior [34]. The mentioned approach would possibly have led to a closer match of the experimental and FEM results of the crash box performance. However, the focus of this investigation was to postulate an inverse material-process-component design method, the component-driven approach, which reverses the process chain perspective. Although this approach did not lead to an increase in energy absorption of $53 \%$ as calculated in the simulations owing to the points already discussed, it may in the future enable a comprehensive, integrative material, process and component design. Thus, resulting in strong lightweight and sustainable construction potential in the future. In addition to the mechanical properties addressed in this paper, this approach makes it possible on the one hand to extend the range of properties and requirements to include for example corrosive, welding and functional properties and on the other hand to fully exploit local property profiles. The authors see further potential to increase the integrated component performance through a numerical consideration of the process control and the associated microstructure evolution. Both the potential transferability of the methodology to other scientific and technical challenges and the flexibility of the approach offer further potential for the presented approach.

\section{Conclusions}

In this paper, a component-driven approach is proposed and demonstrated on a crash box. It was shown that a requirement profile for local material properties derived from the component can lead to energy absorption increase. Starting from a calibrated and validated FE model of the crash box, a corridor of desired material properties could be specified with simulations using artificial material cards and corner-strengthening. Subsequently, isothermal heat treatment strategies and material characterization methods, including lightoptical microstructure, hardness and tensile property measurements, were used to achieve the required property profile and to propose a process window for the process-adapted heat treatment. In order to transfer the given process window to a flexible process with a moving heat source, different heat treatment patterns were characterized using thermal and mechanical investigations, The heat treatment patterns were applied to the crash box corners, to strengthen the corners and enhance the energy absorption. Then, the crash boxes were tested under axial quasi-static compression. The results show an increase in energy absorption by $2.8 \%$ compared to the reference un-heat-treated crash box. Correlating the energy absorption to the dissipation parameter of the heat treatments patterns, a linear trend is observed, which indicates the strong influence of local material properties at the crash box corners on the overall component performance.

The experiment results validate the potential of the inverted process chain; however, the numerical results show a considerably higher energy-absorption increase for the strengthened crash box using the material card 
extracted by the isothermal heat treatment. This difference is related to the limitations of the applied process for local heat-treatment of the crash box; using this process the defined temperatures by the isothermal heat treatment could not be achieved. This process has to be studied and improved further in order to enable the application of this technique in the future. Fast-moving modified welding processes have a good prospect of success in this domain.

Even though the full potential of corner strengthening of crash boxes could not be achieved by the chosen means of process-adapted heat treatment, the inverted process chain showed high potential for integrated design approaches. However, further research is needed to implement additional property requirements and methods such as microstructure evolution and process simulations into the inverted process chain description

Considering the structural behavior, this research shows that local heat treatment has advantages over homogenous heat treatment of a crash box. An increase in the whole crash box stiffness can result in nonprogressive buckling of the crash box. But, the local heat treatment can increase the energy absorption without endangering the progressive-buckling behavior of the crash box.

The effect of corner strengthening on crash box features was studied by conducting parametric studies on the material properties of the corners and the optimal material properties were extracted. The results show high ultimate stress besides a low yield point and low hardening behavior at the beginning of the flow curve not only enhances the crash box energy absorption but also prevents destructive increase of the peak force.

Author Contributions: Conceptualization, N. A., Y. S., J. Z., K. M., R. S., S. M. and K. S.; methodology, N.A., U. R., K. S. and S. M.; software, N. A.; validation, N. A., Y. S., J. Z. and K. M.; formal analysis N. A., Y. S., J. Z. and K. M.; investigation, N. A., Y. S., J. Z. and K. M.; resources, U. R., K. S. and S. M.; data curation, N. A., Y. S., J. Z. and K. M.; writing - original draft preparation, N. A., Y. S., J. Z. and K. M.; writing—review and editing, N. A.; visualization, K. M.; supervision, R. S., U. R., K. S. and S. M.; project administration, U. R., K. S. and S. M.; funding acquisition, U. R., K. S. and S. M. All authors have read and agreed to the published version of the manuscript.

Funding: This research received no external funding.

Conflicts of Interest: The authors declare no conflict of interest.

Data availability: The raw/processed data required to reproduce these findings cannot be shared at this time due to time limitations.

\section{References}

[1] Abramowicz W, Jones N. Dynamic axial crushing of circular tubes. International Journal of Impact Engineering 1984;2(3):263-81. https://doi.org/10.1016/0734-743x(84)90010-1.

[2] Abramowicz W, Jones N. Dynamic axial crushing of square tubes. International Journal of Impact Engineering 1984;2(2):179-208. https://doi.org/10.1016/0734-743X(84)90005-8.

[3] Wierzbicki T, Abramowicz W. On the crushing mechanics of thin-walled structures. J. Appl. Mech. 1983(50(4a)).

[4] Abramowicz W, Jones N. Transition from initial global bending to progressive buckling of tubes loaded statically and dynamically. International Journal of Impact Engineering 1997;19(5-6):415-37. https://doi.org/10.1016/S0734-743X(96)00052-8.

[5] Abramowicz W, Jones N. Dynamic progressive buckling of circular and square tubes. International Journal of Impact Engineering 1986(4):243-70.

[6] H. F. Mahmood and A. Paluszny. Design of thin walled columns for crash energy management - their strength and mode of collapse. SAE International 1981;SAE Technical Paper(811302).

[7] Karagiozova D, Alves M. Transition from progressive buckling to global bending of circular shells under axial impact-Part I: Experimental and numerical observations. International Journal of Solids and Structures 2004;41(5-6):1565-80. https://doi.org/10.1016/j.ijsolstr.2003.10.005. 
[8] Müller B, Schagerl M, Schröder K-U. Prediction of the collapse mode of axially crushed profiles. Proceedings of the Institution of Civil Engineers - Structures and Buildings 2013;166(8):456-64. https://doi.org/10.1680/stbu.12.00058.

[9] Zhang XW, Su H, Yu TX. Energy absorption of an axially crushed square tube with a buckling initiator. International Journal of Impact Engineering 2009;36(3):402-17. https://doi.org/10.1016/j.ijimpeng.2008.02.002.

[10] Liu W, Lian J, Münstermann S, Zeng C, Fang X. Prediction of crack formation in the progressive folding of square tubes during dynamic axial crushing. International Journal of Mechanical Sciences 2020;176:105534. https://doi.org/10.1016/j.ijmecsci.2020.105534.

[11] Singer J, Arbocz J, Weller T. Buckling experiments: Experimental methods in buckling of thin-walled structures; 2002.

658 [12] Jones N. Structural impact. Cambridge: Cambridge University Press; 1990.

[13] Baroutaji A, Sajjia M, Olabi A-G. On the crashworthiness performance of thin-walled energy absorbers: Recent advances and future developments. Thin-Walled Structures 2017;118:137-63. https://doi.org/10.1016/j.tws.2017.05.018.

[14] Karagiozova D, Marcílio A. Dynamic elastic-plastic buckling of structural elements: A review. Applied Mechanics Reviews 2008;61.4:40803.

[15] Singer J, Arbocz J, Weller T. Buckling experiments: Experimental methods in buckling of thin-walled structures. Chichester, New York: Wiley; 1998.

[16] Hanssen AG, Langseth M, Hopperstad OS. Static and dynamic crushing of square aluminium extrusions with aluminium foam filler. International Journal of Impact Engineering 2000.

[17] Meguid S, Stranart J, Heyerman J. On the layered micromechanical three-dimensional finite element modelling of foam-filled columns. Finite Elements in Analysis and Design 2004;40(9-10):1035-57. https://doi.org/10.1016/j.finel.2002.02.001.

[18] Jones N. Energy-absorbing effectiveness factor. International Journal of Impact Engineering 2010;37(6):754-65. https://doi.org/10.1016/j.ijimpeng.2009.01.008.

[19] Rezvani MJ, Jahan A. Effect of initiator, design, and material on crashworthiness performance of thinwalled cylindrical tubes: A primary multi-criteria analysis in lightweight design. Thin-Walled Structures 2015;96:169-82. https://doi.org/10.1016/j.tws.2015.07.026.

[20] Wang C, Li Y, Zhao W, Zou S, Zhou G, Wang Y. Structure design and multi-objective optimization of a novel crash box based on biomimetic structure. International Journal of Mechanical Sciences 2018;138139:489-501. https://doi.org/10.1016/j.jimecsci.2018.01.032.

[21] Jones N, Birch RS. Dynamic and Static Axial Crushing of Axially Stiffened Square Tubes. Proceedings of the Institution of Mechanical Engineers, Part C: Mechanical Engineering Science 1990:293-310.

[22] Yao R, Yin G, Hao W, Zhao Z, Li X, Qin X. Axial buckling modes and crashworthiness of circular tube with external linear gradient grooves. Thin-Walled Structures 2019;134:395-406. https://doi.org/10.1016/j.tws.2018.10.022.

[23] Nikkhah H, Baroutaji A, Olabi AG. Crashworthiness design and optimisation of windowed tubes under axial impact loading. Thin-Walled Structures 2019;142:132-48. 
[24] Shuo L. Impact energy absorption analysis of different thin-walled tubes with and without reinforcement. PhD thesis, University of Manchester 2014.

[25] Huang H, Xu S. Crashworthiness analysis and bionic design of multi-cell tubes under axial and oblique impact loads. Thin-Walled Structures 2019;144:106333. https://doi.org/10.1016/j.tws.2019.106333.

[26] Fang J, Gao Y, Sun G, Zheng G, Li Q. Dynamic crashing behavior of new extrudable multi-cell tubes with a functionally graded thickness. International Journal of Mechanical Sciences 2015;103:63-73. https://doi.org/10.1016/j.jimecsci.2015.08.029.

[27] Li Z, Ma W, Hou L, Xu P, Yao S. Crashworthiness analysis of corrugations reinforced multi-cell square tubes. Thin-Walled Structures 2020;150:106708. https://doi.org/10.1016/j.tws.2020.106708.

[28] Zhang X, Wen Z, Zhang H. Axial crushing and optimal design of square tubes with graded thickness. Thin-Walled Structures 2014;84:263-74. https://doi.org/10.1016/j.tws.2014.07.004.

[29] Xu F, Tian X, Li G. Experimental Study on Crashworthiness of Functionally Graded Thickness ThinWalled Tubular Structures. Exp Mech 2015;55(7):1339-52. https://doi.org/10.1007/s11340-015-9994-3.

[30] Yang RJ, Fu Y, Li G. Application of Tailor Rolled Blank in Vehicle Front End for Frontal Impact. In: SAE Technical Paper Series. SAE International400 Commonwealth Drive, Warrendale, PA, United States; 2007.

[31] Xu F, Sun G, Li G, Li Q. Experimental study on crashworthiness of tailor-welded blank (TWB) thinwalled high-strength steel (HSS) tubular structures. Thin-Walled Structures 2014;74:12-27. https://doi.org/10.1016/j.tws.2013.08.021.

[32] Demirci E, Yildız AR. An experimental and numerical investigation of the effects of geometry and spot welds on the crashworthiness of vehicle thin-walled structures. MP 2018;60(6):553-61. https://doi.org/10.3139/120.111187.

[33] Bambach M, Conrads L, Daamen M, Güvenç O, Hirt G. Enhancing the crashworthiness of highmanganese steel by strain-hardening engineering, and tailored folding by local heat-treatment. Materials \& Design 2016;110:157-68. https://doi.org/10.1016/j.matdes.2016.07.065.

[34] Quadfasel A, Teller M, Madivala M, Haase C, Roters F, Hirt G. Computer-Aided Material Design for Crash Boxes Made of High Manganese Steels. Metals 2019;9(7):772. https://doi.org/10.3390/met9070772.

[35] Conrads L, Liebsch C, Hirt G. Increasing the energy absorption capacity of structural components made of low alloy steel by combining strain hardening and local heat treatment. Procedia Engineering 2017;207:257-62. https://doi.org/10.1016/j.proeng.2017.10.771.

[36] European Aluminium Association. The Aluminuym Automotive Manual - Design for functional performance; 2011.

[37] Hosseini VA, Karlsson L, Hurtig K, Choquet I, Engelberg D, Roy MJ et al. A novel arc heat treatment technique for producing graded microstructures through controlled temperature gradients. Materials \& Design 2017;121:11-23. https://doi.org/10.1016/j.matdes.2017.02.042.

[38] Ituarte IF, Boddeti N, Hassani V, Dunn ML, Rosen DW. Design and additive manufacture of functionally graded structures based on digital materials. Additive Manufacturing 2019;30:100839. https://doi.org/10.1016/j.addma.2019.100839. 
[39] Boddeti N, Tang Y, Maute K, Rosen DW, Dunn ML. Optimal design and manufacture of variable stiffness laminated continuous fiber reinforced composites. Sci Rep 2020;10(1):16507. https://doi.org/10.1038/s41598-020-73333-4.

[40] Gebhardt C, Nellessen J, Bührig-Polaczek A, Broeckmann C. Influence of Aluminum on Fatigue Strength of Solution-Strengthened Nodular Cast Iron. Metals 2021;11(2):311. https://doi.org/10.3390/met11020311.

[41] Ripplinger C, Gastens M, Zimmermann J, Pustal B, Broeckmann C, Schröder K-U et al. Potential of Metallurgical Gradients in the Design of Structural Components Made of Nodular Cast Iron. Materials (Basel) 2021;14(9). https://doi.org/10.3390/ma14092411.

[42] Chen D. Crush mechanics of thin-walled tubes. CRC Press 2015.

[43] Meguid SA, Attia MS, Stranart JC, Wang W. Solution stability in the dynamic collapse of square aluminium columns. International Journal of Impact Engineering 2007;34(2):348-59. https://doi.org/10.1016/j.ijimpeng.2005.09.001.

[44] Jafarzadeh Aghdam N, Tatikonda UBC, Bühring J, Mekala NR, Schröder K-U. Impact of thin - walled square aluminum tubes. Proc. Appl. Math. Mech. 2019;19(e201900395):e201900395. https://doi.org/10.1002/pamm.201900395.

[45] Nima Jafarzadeh Aghdam, Kai-Uwe Schroeder. Effective width and folding size of square crash boxes under impact load. Submitted to International Journal of Impact Engineering 2020.

[46] Chung K, Myoung-Gyu Lee. Basics of Continuum Plasticity. Springer Singapore 2018.

[47] Costas M, Díaz J, Romera LE, Hernández S, Tielas A. Static and dynamic axial crushing analysis of car frontal impact hybrid absorbers. International Journal of Impact Engineering 2013;62:166-81. https://doi.org/10.1016/j.ijimpeng.2013.06.011.

[48] Abaqus/Analysis user's manual, Version 2020; 2020.

[49] Langseth M, Hopperstad OS, Berstad T. Crashworthiness of aluminium extrusions: Validation of numerical simulation, effect of mass ratio and impact velocity. International Journal of Impact Engineering 1999;22:829-54.

[50] Budynas RG, Nisbett JK, Shigley JE. Shigley's mechanical engineering design. New York NY: McGraw-Hill Education; 2015.

[51] Müller B, Schagerl M, Schöder K-U. On the folding of plates which buckle before and beyond the elastic limit. Proc. Appl. Math. Mech. 2013;13(1):111-2. https://doi.org/10.1002/pamm.201310051.

757 [53] Timoshenko SP, Gere JM. Theory of Elastic Stability, 2nd Edition. Mc-Graw-Hill; 1963.

[54] M. Langseth \& O. S. Hopperstad. Local buckling of square thin-walled aluminium extrusions. ThinWalled Structures 1997;27.1:117-26.

[55] Schuman L, Goldie B. Strength of rectangular flat plates under edge compression. NACA Technical Report 1931(356).

(C) 2021 by the authors. Submitted for possible open access publication under the terms and conditions of the Creative Commons Attribution (CC BY) license (http://creativecommons.org/licenses/by/4.0/). 